\title{
Corporate sponsorship of patient groups
}

\author{
It's time for mandatory disclosure
}

\author{
Bethany Bruno medical and bioethics graduate student ${ }^{1}$, Susannah Rose associate chief experience \\ officer and director of research ${ }^{2}$
}

${ }^{1}$ Cleveland Clinic Lerner College of Medicine of Case Western Reserve University, Cleveland, OH, USA; ${ }^{2}$ Office of Patient Experience and Center for Bioethics, Cleveland Clinic, Cleveland, OH, USA

Non-profit patient groups provide support services to patients and families, increase public awareness through educational outreach, participate in the development of clinical guidelines, lobby on policies affecting access and care, and invest in novel research on therapeutics. Although many focus on a particular disease, others focus on the needs and interests of healthcare consumers more generally.

Various sources provide financial assistance, including pharmaceutical and medical device companies. Given the considerable power of patient groups to influence healthcare policy and individual medical decision making, and given research documenting the effects of even small payments on physician practices, ${ }^{1}$ monetary relationships between patient groups and industry have prompted recent concern. In the linked paper (doi:10.1136/bmj.16925), Fabbri and colleagues provide the first systematic review on this topic to examine the extent of ties between patient groups and industry, the policies of patient groups surrounding corporate sponsorship, and the effect of industry support on the public position statements made by patient groups. ${ }^{2}$ This builds on a recent qualitative study in The $B M J$ by Parker and colleagues exploring the attitudes of patient groups towards industry. ${ }^{3}$

Fabbri and colleagues performed a comprehensive meta-analysis of 26 cross sectional studies. Fifteen publications examined the prevalence of corporate sponsorship: between $20 \%$ and $83 \%$ of patient groups were estimated to have relationships with industry, supplying anywhere from a few per cent to near totality of annual operating expenses. Only a quarter of organizations receiving monetary support disclosed this relationship online, and transparency policies were insufficient. At most, only two thirds had organizational policies to regulate industry funding. The results of four studies examining the association between group positions and corporate sponsorship show substantial divergence between funded and non-funded groups, which largely reflect differences in industry versus patient interests. ${ }^{2}$

These findings reveal the breadth and depth of relationships between patient groups and pharmaceutical and medical device companies. The issue is likely even more widespread than portrayed, as included studies only examined relationships with pharmaceutical and medical device companies, excluding connections with the food industry, health insurers, and other companies in the wellness sphere. ${ }^{2}$ Additionally, patient groups are not the only patient voices affected-individuals can become corporate sponsored influencers with no public disclosure of their commercial relationships. ${ }^{4}$

More importantly, these results suggest that financial relationships pose real, not potential, conflicts of interest-with alignment between organizational positions and industry interests even when contrary to patient welfare. This is of particular concern given the power of patient groups internationally. When pharmaceutical and medical device companies lobby political leaders, the financial motivation is readily apparent, but when patient groups or individual patients engage in similar efforts, government and society assume they are acting independently in the interests of patients. ${ }^{5}$

Patient groups also may provide a channel through which companies can target patients in the many countries where direct-to-consumer advertising is illegal. As Parker and colleagues noted in their previous study, when a patient group does not already exist, companies have been known to establish one, placing carefully selected leaders at the top. In qualitative interviews with patient group staff, the leaders readily acknowledged the "give and take," transactional nature of corporate sponsorship. ${ }^{3}$ Patient organizations have been slow to regulate their own conflicts of interest; perhaps these intimate connections explain the holdup. Society's sympathy for patients' lived experiences might also underpin hesitancy to legislate in this sphere.

Fortunately, the beginnings of a solution have already been developed and implemented by governments in another context. Patient groups are not the only branch of corporate influence in medicine; about $48 \%$ of American physicians receive a total of $\$ 2.4 \mathrm{bn}\left(£ 1.8 \mathrm{bn} ; € 2.1 \mathrm{bn}\right.$ ) annuallyin payments from industry. ${ }^{6}$ Acknowledging the potential for undue influence as well as the failure of voluntary policies, particularly among those receiving large payments, " "sunshine" acts in the US and several European 
countries mandate disclosure of payments to physicians to promote transparency. ${ }^{89}$ Although not a cure-all, disclosure upholds moral commitments to honesty and integrity while providing a starting point from which governments and the public can begin to recognize and interpret industry's influence. ${ }^{10}$

Fabbri's and Parker's teams provide yet more evidence that conflicts of interest between patient groups and industry are extensive and run deep. Voluntary disclosure is not working. It is time for mandatory disclosure-only then can stakeholders explore how best to respond to disclosed information and develop additional legislative safeguards as needed to fortify public trust.

Competing interests: We have read and understood the BMJ Group policy on declaration of interests and declare the following interests. SLR has received speaking honorariums and travel funding in the past three years from Siemens Healthineers, Panagora Pharma, Healthcare Information and Management Systems Society, Next Generation Patient Experience, and healthcare systems in Sweden and Saudi Arabia. These lectures are not related to the content of this editorial. She also served on the ethics committee for the American Society of Clinical Oncology, a non-profit professional organization in the US, for a two year term ending in fall 2019.
Provenance: Commissioned; not peer reviewed.

1 DeJong C, Aguilar T, Tseng CW, Lin GA, Boscardin WJ, Dudley RA. Pharmaceutical industry-sponsored meals and physician prescribing patterns for Medicare beneficiaries. JAMA Intern Med 2016;176:1114-22. 10.1001/jamainternmed.2016.2765. 27322350

2 Fabbri A, Parker L, Colombo C, etal . Industry funding of patient and health consumer organisations: systematic review with meta-analysis. BMJ 2020;368:16925.

3 Parker L, Fabbri A, Grundy Q, Mintzes B, Bero L. "Asset exchange"-interactions between patient groups and pharmaceutical industry: Australian qualitative study. BMJ 2019;367:I6694. 10.1136/bmj.16694. 31831471

4 Butler J, Fugh-Berman A. Patient influencers paid by pharmaceutical companies should be required to disclose industry ties. Health Affairs Blog 2020. https://www.healthaffairs. org/do/10.1377/hblog20200109.985594/full/. Accessed January 14, 2020. 10.1377/hblog20200109.985594

5 Rose SL. Patient advocacy organizations: institutional conflicts of interest, trust, and trustworthiness. J Law Med Ethics 2013;41:680-7. 10.1111/jlme.12078. 24088159

6 Tringale KR, Marshall D, Mackey TK, Connor M, Murphy JD, Hattangadi-Gluth JA. Types and distribution of payments from industry to physicians in 2015. JAMA 2017;317:1774-84. 10.1001/jama.2017.3091. 28464140

7 Hawkes N. Doctors getting biggest payments from drug companies don't declare them on new website. BMJ 2016;354:i3679. 10.1136/bmj.i3679. 27371034

8 Agrawal S, Brennan N, Budetti P. The Sunshine Act--effects on physicians. N Engl J Med 2013;368:2054-7. 10.1056/NEJMp1303523. 23718163

9 Santos Al. The sun shines on Europe: Transparency of financial relationships in the healthcare sector. Health Action International, 2017.

10 Bruno B, Rose S. Patient organizations and conflict of interest. BMJ 2019;364:1129. 10.1136/bmj.1129. 30651230

Published by the BMJ Publishing Group Limited. For permission to use (where not already granted under a licence) please go to http://group.bmj.com/group/rights-licensing/ permissions 